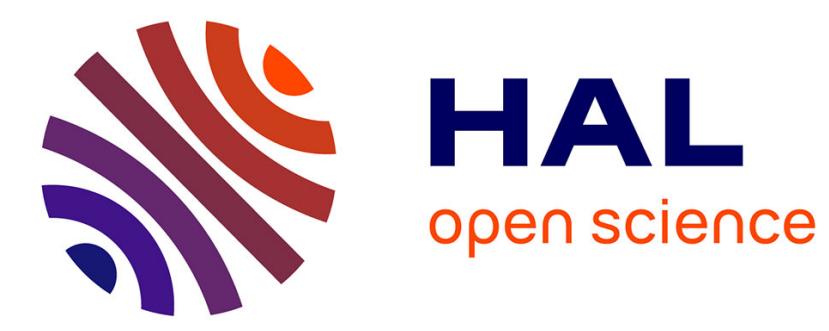

\title{
MASS CUSTOMIZATION FOR CULTURAL HERITAGE 3D MODELS
}

Matthieu Quantin, Benjamin Hervy, Florent Laroche, Jean-Louis Kerouanton

\section{To cite this version:}

Matthieu Quantin, Benjamin Hervy, Florent Laroche, Jean-Louis Kerouanton. MASS CUSTOMIZATION FOR CULTURAL HERITAGE 3D MODELS. Digital Heritage, Sep 2015, Granada, Spain. 2, 2015, Digital Heritage 2015. 10.1109/DigitalHeritage.2015.7419469 hal-01223129

\section{HAL Id: hal-01223129 \\ https://hal.science/hal-01223129}

Submitted on 4 Nov 2015

HAL is a multi-disciplinary open access archive for the deposit and dissemination of scientific research documents, whether they are published or not. The documents may come from teaching and research institutions in France or abroad, or from public or private research centers.
L'archive ouverte pluridisciplinaire HAL, est destinée au dépôt et à la diffusion de documents scientifiques de niveau recherche, publiés ou non, émanant des établissements d'enseignement et de recherche français ou étrangers, des laboratoires publics ou privés.

\section{(1)(1) $\$(0)$}

Distributed under a Creative Commons Attribution - NonCommercial - ShareAlikel 4.0 


\section{MASS CUSTOMIZATION FOR CULTURAL HERITAGE 3D MODELS}

\author{
Matthieu Quantin \\ IRCCYN UMR CNRS 6597 \\ École Centrale de Nantes \\ Nantes, France
}

\author{
Benjamin Hervy \\ IRCCyN UMR CNRS 6597 \\ École Centrale de Nantes \\ Nantes, France
}

\author{
Florent Laroche \\ IRCCyN UMR CNRS 6597 \\ École Centrale de Nantes \\ Nantes, France
}

\author{
Jean-Louis Kerouanton \\ Centre François Viète \\ Université de Nantes \\ Nantes, France
}

\begin{abstract}
Digital technologies in the last twenty years have offered cultural heritage $(\mathrm{CH})$ new possibilities in conservation and promotion. 3D digitization has especially become more and more affordable and efficient. This leads to massive digitization projects and increasing amount of $\mathrm{CH}$ digital data. As an engineering team working on industrial techniques for reverse engineering, we are deeply affected by this effect. In this paper we propose a way to combine semantic information on top of the acquisition and modeling steps in order to manage heterogeneous historical data. We illustrate our approach with a use case composed of three overlapping historical objects related to Nantes' harbour history.
\end{abstract}

Index Terms-Industrial heritage, knowledge management, 3D modeling, information visualization, levels of detail.

\section{Introduction}

Considering the amount of overlapping 3D digitized models of cultural heritage $(\mathrm{CH})$ objects, connecting their references would enrich every one of them and optimize historical research process. Focused on technical and industrial heritage, this paper describes a process from mass digitization to mass customization. Indeed, modeling the context make digitized artifact become unique and customized rather than a 3D mesh among others. The context also provides a way to explore the system the technical objects belong to. Three variables are considered: temporal, spatial and thematic. Each one includes several levels of detail:

- The temporal dimension can be related to a short period of time (machinery production cycle), an intermediate period (machinery lifecycle in the factory) or even a long period (the whole lifecycle including the functioning period and its lifecycle as an heritage object).

- The spatial dimension can be related to both the geometric shape and the geographical area. Although a $\mathrm{CH}$ object can have no specific position (e.g. vehicles, steam engine or any generic technical object), it is linked to one or more geographical environments.

- The thematic dimension is not finite and can be related to many research domains: social, economics, mechanics, aesthetic, etc. This aspect is significant to understand different points of view on the object.
The main issues lie in the management of historical knowledge and the access to information. Many projects such as [1] deal with the management of archeological data and try to provide semantic access to geographical information. In our case, we deal with narrower scales and focus on the analysis of an object and its context. We mostly work on the object as part of a technical system. Our approach assumes that historical knowledge should not depend on physical representation (such as a 3D model) quality [2]. Nevertheless, it can enhance the information system with the object geometrical features. This paper discusses the idea of making connexions between the physical object and a knowledge database. This connection allows identification of lacks of information, and cross navigation through the three variables mentioned above. In addition, semantic keyword navigation is possible.

We study Nantes' (french city) harbour history through three different historical objects (see Fig. 1). This use case leads us to those considerations.

Based on this use case of conservation and promotion of cultural and industrial heritage, we wanted to make connexions between the different pieces of information, gathering the knowledge capitalized regarding the parts of the use case. Theses connexions make possible to manage artifacts' physical representations (3D, dynamic simulations) based on available knowledge (and not the contrary). Combining both historical sources and produced knowledge (under the form of 3D models or written analysis) would allow researchers and broad public to explore different scales and dimensions of the objects

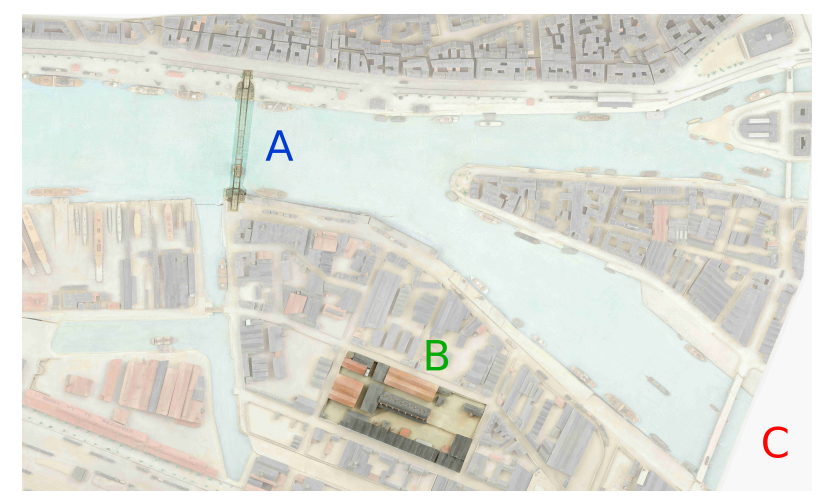

Fig. 1: Geographical positioning of three studied objects between 1899 and 1913: the global area represents a part of Nantes harbour (C), and the two other objects (highlighted): Transporter bridge (A) and "Halles Alstom" (B). 
involved. Because we believe 3D representations should create at least as many questions as it answers, our proposal should be a way to identify historical research hypothesis.

\section{Methodology: Multi-dimension knowledge modeling process}

3D digitization has especially become more and more affordable and efficient. This leads to massive digitization projects and increasing amount of cultural heritage $(\mathrm{CH})$ digital data [3]. Every project in $\mathrm{CH}$ conservation and promotion we are involved into implies the creation of new historical knowledge under the digital form. Many of them have implicit links: geography, time, thematics. Therefore, we want to manage $\mathrm{CH}$ objects uniqueness by creating connexions in order to access information through different dimensions. This is what we call "mass customization for cultural heritage objects".

We state here that every historical object can be represented by a combination of the three axis of Fig. 2 according to common practices in industrial archaeology [4], [5].

Therefore, we propose a methodology based on the creation of relationships between descriptive pages dedicated to cultural objects and these 3 axis. First, we create a descriptive page. This descriptive page is a classical historian's production composed of full text document with historical sources. Thus, this work is subjective so we aim to confront it to other ones. Based on the content, we link this page with other ones through the identification of common keywords. This linking step can be semi-automatic thanks to text mining techniques such as named entity recognition. Then, we attach three variables for the positioning of the descriptive page in the Space-Time-Thematic cube. The thematic dimension can be deduced from the previous step of keywords identification. The spatial positioning can be divided into three parts :

1) Mandatory association between the descriptive page and geographic area(s). Whenever this kind of information is not avalaible, the information system has to highlight this page as incomplete. This would allow users to identify potential research axis.

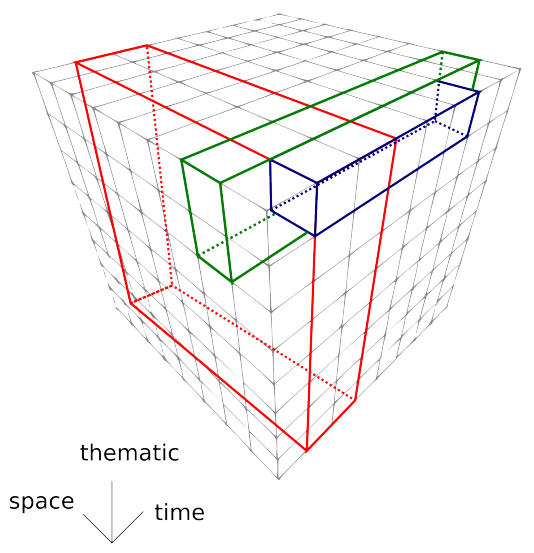

Fig. 2: Schematic representation of the Space-Time-Thematic cube. Three historical objects are represented in different colors to illustrate possible cross referencing: Nantes1900 in red, Halles Alstom in green and Transporter bridge in blue.
2) Potential association between a $3 \mathrm{D}$ part and other spatial information (map, 3D part, etc.)

3) Potential association between descriptive page and 3D part (when available)

This methodology implies that every descriptive page can be defined on Fig. 2 by a group of blocks. Considering our three use cases, they gather a group of descriptive pages (blocks). On Fig. 2, we represent 3 volumes corresponding to an average of all these blocks for each use case.

Our approach needs to be adaptative to different historical data (physic and semantic) acquisition processes. The objective is to model information in order to combine the three dimensions represented on Fig. 2. 3D physical information is not attached to any thematic but to space and time. Our methodology allows to switch from mass digitization to mass customization of virtual artifacts. Virtual artifacts can be both physical or semantic/abstract representation about studied objects.

Once the user accesses a descriptive page, the system provides links according to neighbouring blocks on Fig. 2 and keywords cooccurrences. This way, the user is able to navigate all around his first search. He can explore combined, dynamic $3 \mathrm{D}$ environments and semantic networks. The cube is not an user interface, but define what we call the "neighbourhood" of a piece of information.

\section{Use case presentation: heterogeneous data}

In addition to the 3 dimensions mentioned in section II, we also have to deal with heterogeneous historical materials ${ }^{1}$. Three industrial archaeology studies compose our use case and illustrate this double issue. Yet, our proposition aims to be applied to any other cultural heritage study of this kind.

a) "Nantes 1900" project: a museum project focusing on industrial heritage through the case of a 100 years old scale model. This scale model is part of Nantes (France) history museum. In this project, we have a delimited spatial area which is the harbour of a city. We also have many heterogeneous historical documents related to hundreds of points of interest. The 3D model of the physical scale model comes from scanner digitization (Creaform HandyScan). It is composed of 100 million points. In addition, we gathered a corpus of 1000 historical documents (postal cards, archives documents, paints, photographies, books, etc.) and hundreds of notes written by historians. Based on this corpus, we created a knowledge database to handle these information.

The global level of detail is related to the city scale approximately between 1899 and 1920 . The database stores information about many thematics related to industrial activity: social ("labour conditions in the early 1900's", people biographies), economics (companies' chronicle), technology (shipyards, steam engines), architecture and urbanism (urban network), etc.

b) "Halles Alstom": an industrial complex being restorated and based in the harbour of Nantes. This historical "object" is part of the scale model mentioned above. In this case, we have a detailed historical analysis that lead to a

\footnotetext{
${ }^{1}$ Heterogeneity concerns sources types, analysis nature, levels of detail, object nature, temporalities of the object
} 

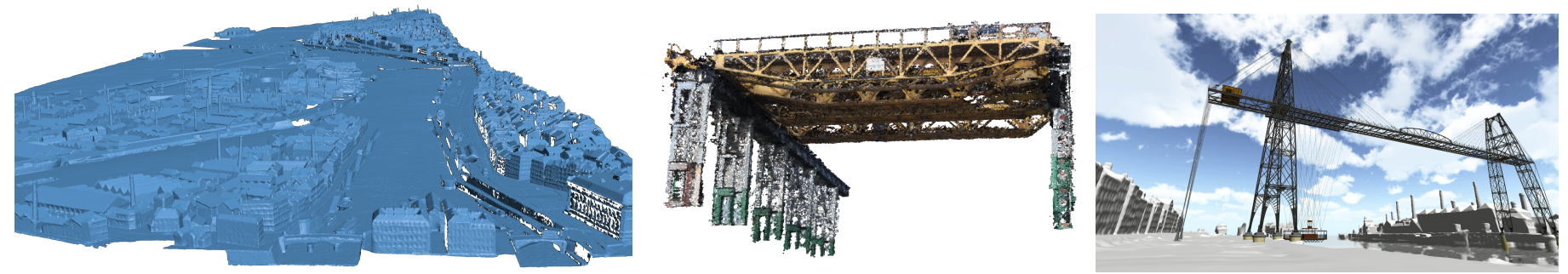

Fig. 3: Use cases' 3D models with different acquisition techniques : 3D scan, photogrammetry, and 3D reconstruction (CAD model).

monography (master thesis). We also have specific historical documents such as 3D models coming from photogrammetry (using Agisoft Photoscan). This analysis focuses on an area related to a factory scale, but with a broader time period (1850-2001). Compared to the Nantes 1900 project, only some thematics are covered: technology (mechanics, materials), architecture and urbanism.

c) Nantes transporter bridge: a bridge present on the harbour area from 1903 to 1958. Based on historical and technical archives, we created a functional CAD 3D model. This 3D model can simulate the transporter bridge during its functioning cycle. On this object, the different dimensions taken into account are smaller: the geometry is related to a single industrial element, and the thematic dimensions focus on its technical and aesthetic aspect.

\section{Concrete application}

\section{A. Results of semantic integration for $3 \mathrm{D} \mathrm{CH}$ models}

In order to illustrate our methodology described in section II, we present here seven descriptive pages (among the hundreds we have for our three use cases) and the way they connect in the system.

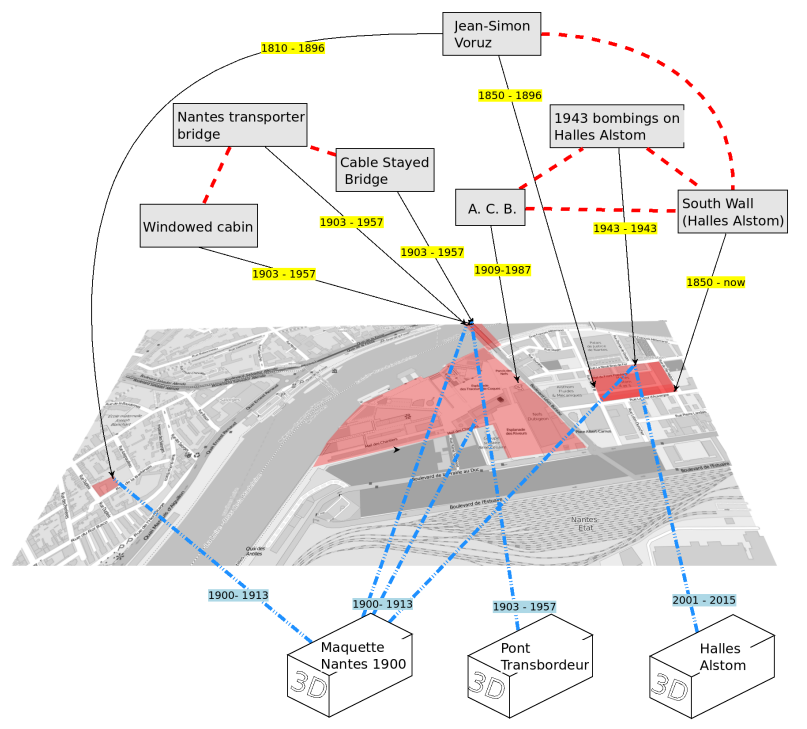

Fig. 4: Schematic representation of the relationships between 3D models, semantic information and spatio-temporal data.
Nantes 1900: 3 descriptive pages: Jean-Simon Voruz, a businessman who set up a foundry in 1850 on the "Halles Alstom" site, Nantes transporter bridge, Ateliers et chantiers de Bretagne, one of the most important shipyards of Nantes in the twentieth century.

Halles Alstom: 2 descriptive pages: the south wall, and the 1943 bombings on Halles Alstom.

Transporter Bridge: 2 descriptive pages: the windowed cabin and the category of cable-stayed bridges.

Fig. 4 represents an image of the whole proposed system simplified with the example of the 7 previously mentioned descriptive pages. Historical studies focus on specific subject leading to a particular research context. Such context is marked out with temporal, spatial and thematic boundaries. When the user selects a descriptive page, the system provides a set of connexions with other pages based on keywords cooccurences. Resulting network has spatial, temporal, thematic and semantic features according to the cube Fig. 2. In addition, some of the network's elements can be connected to 3D models. This model is a way to navigate between different levels of detail and dimensions.

In our example above, one possible keyword query returns 3 descriptive pages ("1943 bombing on Halles Alstom", "Halles Alstom" and "Nantes transporter bridge"). Then, the user can choose one of them (e.g. "Nantes transporter bridge"). Finally, the system provides all the related content (text analysis, historical sources and 3D models), and the context of the user selection. This context includes semantic linked pages ("windowed cabin", "cable-stayed bridges") and a spatiotemporal-thematic neighbourood. Neighbourhood criteria are defined by the user (e.g. "5 to 10 years" and/or "less than 500 meters").

\section{B. Proposal of virtual reality based interface}

We propose several solutions to explore this heterogeneous data. First, the user can navigate in the virtual scene: it allows to visualize semantic and spatio-temporal information through different points of view (place, date, thematics).

The user can select several descriptive pages as a group. Then, he can choose to highlight the entire group to quickly see the locations of items of interest.

Each descriptive page (Figure 5) can show the evolution of the item selected through time. The user can choose a period of time within the available data and check the details relevant to 
this age. It can be a different picture, 3D model or a different description for example.

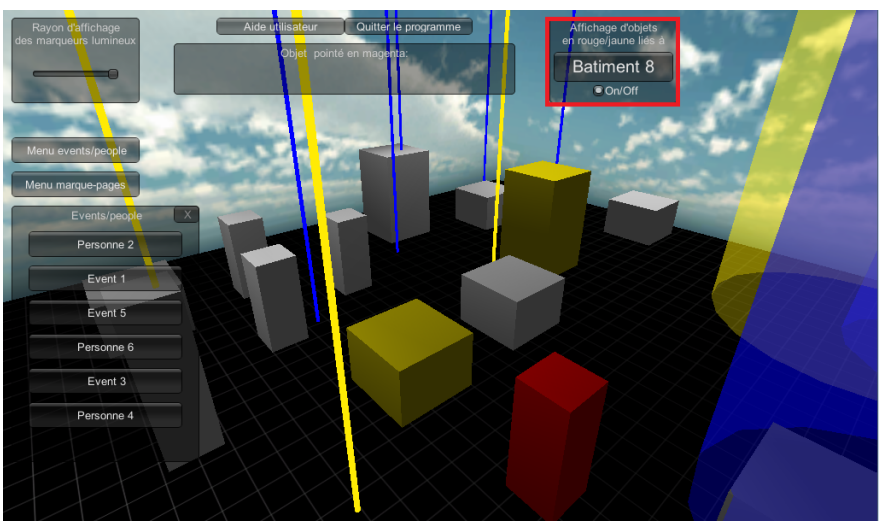

Fig. 5: Visualizing connexions between items in the virtual scene based on database information.

If we combine all these data types, the interface and the visualization can become messy and non-efficient. The solution would be to use filters and layers to show only what the historian is interested in at the moment. For example, our prototype proposes a cursor to adjust the vizualisation area around the user, allowing to manage the number of semantic details.

\section{Conclusion}

This paper proposes a way to manage structured historical information combining 3D models, spatio-temporal data and semantic information. Descriptive pages as defined in this paper are the core of this framework because they fit with historian working methods. The use cases we mentioned highlight the usefullness of our system. They show there is a significant interest in navigating through different dimensions (see Fig. 2), and levels of detail, regardless of a 3D model representation. The system allows the historians to create and visualise connexions, based on existing knowledge elements, in order to identify research issues among other things. 3D models finally come as additive tool.

Our approach presents some limits due to the complexity of historical information and 3D models post-processing (which currently is mostly manual). Next step is to improve the linking process so that it would be transparent for historians. We need to find a compromise between automatic and manual processing because of the necessary validation of historical information. Indeed we have to avoid a blackbox system.

Semantically enriched 3D cultural heritage models [6] could be a way to improve visualisation of information within the $3 \mathrm{D}$ model. It would allow end users to navigate from the $3 \mathrm{D}$ model to the semantic network and vice versa. Another improvement lies in the possibility for users to specialize information models both for semantic (specific ontology) and spatio-temporal data (for example CityGML urban models [7]).

Contextualizing historical objects is a common issue. Dealing with tied historical use cases, our approach aims at providing a common framework to combine them. This makes crossings possible between knowledge elements related to these historical objects. Thus, each object helps with contextualizing the others.

\section{References}

[1] A. Karmacharya, C. Cruz, F. Boochs, and F. Marzani, "ArchaeoKM: Managing Archaeological data through Archaeological Knowledge," in Conference on Computer Applications and Quantitative Methods in Archaeology, 2010. [Online]. Available: http://hal-univ-bourgogne. archives-ouvertes.fr/hal-00639597

[2] F. Laroche, A. Bernard, and M. Cotte, "Advanced Industrial Archaeology: A new reverse-engineering process for contextualizing and digitizing ancient technical objects," Journal Virtual and Physical Prototyping, vol. 3, no. Special Issue n $\backslash$ degre2, pp. pp.105-122, 2008. [Online]. Available: http://hal.archives-ouvertes.fr/hal-00422162

[3] A. Addison, "Emerging trends in virtual heritage," MultiMedia, IEEE, 2000. [Online]. Available: http://ieeexplore.ieee.org/xpls/abs \all.jsp? arnumber $=848421$

[4] P. Martin, "Industrial Archaeology," in International Handbook of Historical Archaeology, D. Gaimster and T. Majewski, Eds. New York, NY: Springer New York, 2009, pp. 285-297. [Online]. Available: http://www.springerlink.com/index/10.1007/978-0-387-72071-5

[5] B. Trinder, "Industrial archaeology: a discipline?" in Industrial Heritage Re-tooled. The TICCIH guide to Industrial Heritage Conservation, J. Douet, Ed. TICCIH, 2012, ch. 3, pp. 24-30.

[6] S. Maass and J. Döllner, "Seamless integration of labels into interactive virtual 3D environments using parameterized hulls," in Proceedings of the Fourth Eurographics conference on Computational Aesthetics in Graphics, Visualization and Imaging. Eurographics Association, 2008, pp. 33-40. [Online]. Available: http://dl.acm.org/citation.cfm?id= 2381340

[7] E. Costamagna and A. Spanò, "CityGML for Architectural Heritage," in Developments in Multidimensional Spatial Data Models. Springer Berlin Heidelberg, 2013. [Online]. Available: http://link.springer.com/ chapter/10.1007/978-3-642-36379-5\_14 